\title{
Examination the Effects of Aerobic and Resistance Exercise on Body Compositions of Sedentary Male Individuals
}

\author{
Niyazi Sıdkı Adıgüzel ${ }^{1}$, Umut Canli $^{2}$ \\ ${ }^{1}$ Presidency of the Republic of Turkey, Ankara, Turkey, \\ ${ }^{2}$ School of Physical Education and Sports, Tekirdag Namık Kemal University, Tekirdag, Turkey \\ Correspondence: Umut Canli, School of Physical Education and Sports, Tekirdag Namık Kemal University, Tekirdag, \\ Turkey.
}

Received: January 15, 2019

doi:10.11114/jets.v7i3S.4007
Accepted: January 29, $2019 \quad$ Online Published: January 30, 2019

URL: https://doi.org/10.11114/jets.v7i3S.4007

\begin{abstract}
The present study was conducted to determine the effects of 8-week aerobic and resistance training on body composition values of sedentary male individuals. A total of 30 healthy sedentary male subjects volunteered to participate in the study and were divided into two groups randomly: aerobic training group $(n=15$, age $=34.0 \pm 5.22$ years $)$, and resistance training group $(\mathrm{n}=15$, age $=34.2 \pm 6.12)$. Body heights of the participants were measured and their body compositions body weight (BW), body mass index (BMI), basal metabolic rate (BMR), body fat percentage (BFP), body fat mass (BFM), lean body mass (LBM) were measured with bioelectric impedance analysis (BIA) device, and then evaluated. Their resting heart rates were determined, and maximum heart rates were calculated with the Karvonen formula. The Brzycki Equation was used to predict one-repetition maximum strength. There were statistically significant decreases in $\mathrm{BW}, \mathrm{BMI}, \mathrm{BFP}$ and BFM values of the aerobic training group $(\mathrm{p}<0.05)$. There was no significant difference between preand post-test values of BMR and LBM $(\mathrm{p}>0.05)$. BW and BMI values of the resistance training group did not show a significant difference in pre-test and post-test $(\mathrm{p}>0.05)$. Significant decreases were found in BFP and BFM values $(p<0.05)$. The increase in BMR and LBM values were found to be statistically significant $(p<0.05)$. There were significant differences between BW, BMI, BMR, BFM and LBM values in the comparison of pre- and post-test values of the aerobic and resistance training groups $(\mathrm{p}<0.05)$. However, there was no statistically significant difference in BFP $(\mathrm{p}>0.05)$. In conclusion, it was found out that regular aerobic and resistance training caused positive effects on body composition of sedentary male individuals.
\end{abstract}

Keywords: aerobic exercise, resistance exercise, body composition, sedentary male, body fat mass

\section{Introduction}

Physical inactivity caused by industrialization and modern lifestyle negatively affects individuals in every age group. A sedentary lifestyle comes with serious health problems. Especially sedentary middle-aged and old individuals experience several health problems, such as high blood pressure, muscular weakness, postural disorder, diabetes, increased coronary artery risk factors, and losses in chest elasticity, respiratory capacity and abdominal muscle strength. Moreover, they present complaints such as digestion and excretion difficulties, loss of strength, flexibility and durability in all muscles, fatigue, loss of function in basic motor skills, loss of bone mineral density, osteoarthritis, increased blood sugar and blood lipid level and obesity. Besides, the physical and mental problems of obesity are the adverse effects of long-term sedentary life in the organism (Utter et al., 2000; Zorba, 1999).

A sedentary lifestyle may lead to a disruption of energy balance and, thus, to obesity. Obesity is characterized by high rates of fat and endomorphism. Especially, if the body weight exceeds the normal limits, many serious health problems, as well as a decrease in physical work capacity, may be experienced (Carter and Heath, 1990). People who do exercises are expected to have some physiological changes, as well as both acute and chronic adaptations. It is emphasized that regular, long-term aerobic training with moderate intensity reduces obesity, one of the risk factors of coronary artery risk factors (Akgün, 1995; Fox, Bowers \& Foss, 2012; Lemura \& Amdreacci, 2000). There are studies revealing that long-term aerobic training programs improve aerobic capacity in both men and women and reduce body fat (Katzmarzyk et al., 2001; Osei-Tutu and Campagna, 2005). However, there are some studies suggesting that aerobic training does not cause significant changes in body compositions of middle-aged women and men despite the improvements in aerobic capacity 
(Murtagh, Boreham, Nevil, Hare \& Murphy, 2005; Büyükyazı et al., 2005). The most effective training types against health risks are walking, jogging, mountain hiking, cycling, rowing and swimming. Aerobic training is also relatively efficient to eliminate health problems such as obesity, cardiovascular diseases and bone deformations (Zorba, 1990).

There are some studies in the literature conducted on the effects of strength training on body compositions. In their study, Harbili et al. (2005) observed changes in body compositions of the participants after 6-week strength training. There was no significant change in body weights between the pre- and post-training period, but a significant decrease in body fat percentage and an increase in lean body mass were observed. Studies in the literature also suggest that resistance training increases fat-free body weight and reduces body fat percentage (Savaş and Sevim, 1992; Terry, Glen, Roger, Craig \& William 1998; Elam, Hardin, Suttan \& Hagen 1998; Kurter \& Öztürk, 1991). Eric et al. (2000) stated that resistance training increases lean body mass but did not alter body fat.These findings related to body composition reveal that resistance training increases lean body weight with an anabolic effect while causing changes in body composition by decreasing body fat percentage (Harbili, Özergin, Harbili \& Akkuş, 2005).

As it is clear, when evaluated separately, both types of training have positive effects on body composition. Thus, the aim of this study is to make between- and within-group comparisons of aerobic and resistance training groups, which are composed of sedentary male individuals, in terms of body composition elements after the training programs.

\section{Materials and Methods}

\subsection{Subjects}

A total of 30 healthy sedentary male subjects volunteered to participate in the study and were divided into two were divided into two groups as randomized: aerobic exercise group $(\mathrm{n}=15$, age $=34.0 \pm 5.22$ years $)$, and resistance exercise group $(\mathrm{n}=15$, age $=34.2 \pm 6.12)$. Exclusion criteria were chronic ankle instability and any lower extremity musculoskeletal injuries in the previous 6 months. All testing and exercise procedures were fully explained, and subjects signed written informed consent before begin of the study. The study was conducted according to the declaration of Helsinki.

\subsection{Measurements}

\subsubsection{Body Height Measurement}

A wall-mounted stadiometer with a precision of $0.1 \mathrm{~cm}$ was used for height measurement. Measurements of the participants were taken in a way that feet were naked, body weight was evenly distributed on both feet, heels were in contact with the stadiometer, the head was in Frankfort plane, and arms were hanged freely from the shoulders (Özer, 2009) two last trials.

\subsubsection{Body Composition Measurement}

Body compositions of the participants were measured and evaluated with a bioelectrical impedance analysis (BIA) (Tanita BC 418 MA). BIA is a method of body composition analysis based on the progression of electricity through body tissues and the poor conductivity of adipose tissue. The measurements were recorded on an empty stomach in the morning, with empty bladder and intestines and in an upright position. The measurement includes body weight (BW), body mass index (BMI), basal metabolic rate (BMR), body fat percentage (BFP), body fat mass (BFM), and lean body mass (LBM) (Kaya \& Özçelik, 2009).

\subsubsection{Resting and Maximum Heart Rate Measurements}

After resting for 15 minutes in the supine position, resting heart rates of the participants were measured with Omran M2 automatic blood pressure monitor in a sitting position. Heart rate is based to determine the aerobic training load. Maximum heart rates of the participants were calculated with the Karvonen formula (Karvonen, Kentala \& Mustala, 1957). During training, heart rates of the participants were checked with the Polar® H7 telemetry pulse meter device.

\subsubsection{One-Repetition Maximum (1RM) Strength Measurement}

In the test, the subject jumped from a standing position using a countermovement (Brzycki, 1993). The participants' standing reach was recorded before the initial jumps took place. To measure vertical reach, each subject stood beside the instrument and extended her dominant arm over her head without lifting her heels off the ground. This height was recorded and later subtracted from the maximum height jumped to calculate the subject's vertical jump. Participants performed each jump 3 times, and the average of the 3 trials was recorded. changes in the values were recorded.

\subsection{Procedures}

At the beginning of the study, the groups were informed about their training sessions. Body heights of 30 participants were measured and body compositions were determined with bioelectrical impedance method on an empty stomach in the morning, with empty bladder and intestines and in an upright position. Resting pulse values of the aerobic training 
group were measured. Aerobic exercise load was determined based on heartbeats and Karvonen formula was used for the calculation. The aerobic exercise group performed a 30-minute aerobic training with the help of a treadmill (20 minutes) and elliptical trainer (10 minutes). The intensity of aerobic training was determined based on $55-60 \%$ of maximum heart rate of the aerobic training group in the first 4 weeks and $60-65 \%$ in the second 4 weeks.

$1 \mathrm{RM}$ of the resistance exercise group was determined before the 8-week training program to be administered to it. In the first 4 weeks of resistance exercise, the group participated in the training sessions based on $40-50 \%$ of their maximums. 1RM of the group was measured once again at the beginning of the second 4 weeks and the second 4-week resistance exercise was performed based on 50-60\% of their maximums (Chest Press, Lat Pull Down, Machine Shoulder Press, Triceps Push Down, Biceps Curl, Leg Curl, and Leg Extension, respectively (3 sets of 12 reps)). The participants rested between the sets for twice as long as the load sessions, and between the stations for 3-5 minutes. Weight machines were used in all training sessions. At the end of both training sessions, a 5-minute stretching exercise (cool-down) was done by the participants accompanied by the researcher and the session was completed. Participants were told not to make any changes in their eating habits. At the end of 8 weeks, height measurements of the aerobic and resistance exercise groups were made, and their body composition values were determined with BIA. Finally, changes in the values were recorded.

\section{Data Analysis}

All statistical analyses were performed using the SPSS version 21.0 software (Statistical Package for Social Sciences; SPSS Inc., Chicago, IL, USA). The mean and standard deviation values of the participants were determined by descriptive statistics. The normality of the distribution was tested by the Shapiro Wilk test and all data were normally distributed, and therefore, paired sample t-test was used to detect differences for each test between the pretest and posttest to determine statistical significance. Independent $t$-test has been used to evaluate the difference between groups before and after training for each parameter. The level of significance was set at $\mathrm{p} \leq 0.05$.

\section{Results}

Descriptive statistics on the aerobic and resistance exercise groups and the total number of participants are presented in Table 1.

In the comparison of the pre-and post-test values related to body compositions of the aerobic exercise group, it was found that there were significant decreases in BW and BMI values at the end of the 8-week aerobic exercise $(\mathrm{p}<0.05)$. In addition, there were statistically significant decreases in BFP and BFM values $(p<0.05)$. However, there was no significant difference between pre-and post-test values related to BMR and LBM ( $p>0.05$ ) (Table 2).

No significant difference was found between pre-test and post-test values related to BW and BMI at the end of the 8-week resistance exercise administered to the resistance exercise group ( $p>0.05$ ). Besides, decreases in BFP and BFM values and increase in BMR value were found to be statistically significant $(\mathrm{p}<0.05)$. At the end of resistance exercise, it was found out LBM values of the resistance exercise group increased, and such an increase was found to be statistically significant $(\mathrm{p}<0.05)$ (Table 3).

Significant differences were found in BW, BMI, BMR, BFM, and LBM values according to the comparison of pre-test and post-test values related to body compositions of the aerobic and resistance exercise groups $(p<0.05)$. However, no statistically significant difference was found in BFP values ( $p>0.05$ ) (Table 4).

Table 1. Statistical Data of Participants' Descriptive Values

\begin{tabular}{lcccccc}
\hline \multirow{2}{*}{ Variables } & \multicolumn{2}{c}{ Aerobic Exercise Group } & Resistance Exercise Group & \multicolumn{2}{c}{ Total Group } \\
& \multicolumn{2}{c}{$\mathbf{n = 1 5}$} & \multicolumn{2}{c}{$\mathbf{n = 1 5}$} & \multicolumn{2}{c}{$\mathbf{n = 3 0}$} \\
\cline { 2 - 7 } Age (year) & Mean & Sd & Mean & Sd & Mean & Sd \\
Body height $(\mathbf{c m})$ & 34.0 & 5.22 & 34.2 & 6.12 & 34.1 & 5.67 \\
\hline
\end{tabular}

$\mathbf{c m}=$ centimeter; $\mathbf{n}=$ number of participants; $\mathbf{S d}=$ standard deviation 
Table 2. Comparison of Pre-Test and Post-Test Values of Body Composition in the Aerobic Exercise Group

\begin{tabular}{|c|c|c|c|c|c|c|c|}
\hline \multirow{2}{*}{ Variables } & & \multicolumn{2}{|c|}{ Pre-Test } & \multicolumn{2}{|c|}{ Post-Test } & \multirow{2}{*}{$\mathbf{t}$} & \multirow{2}{*}{$\mathbf{p}$} \\
\hline & & Mean & Sd & Mean & Sd & & \\
\hline \multirow{6}{*}{ 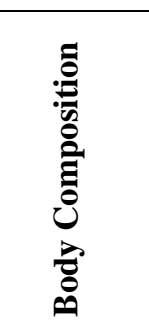 } & Body weight (kg) & 94.8 & 13.99 & 91.7 & 11.73 & -2.784 & $0.005^{*}$ \\
\hline & BMI $\left(\mathrm{kg} / \mathrm{m}^{2}\right)$ & 28.6 & 2.51 & 27.6 & 1.78 & -2.758 & $0.006^{*}$ \\
\hline & BMR & 2179.1 & 306.93 & 2155.9 & 269.81 & -1.108 & 0.268 \\
\hline & ВFP \% & 22.4 & 4.16 & 20.1 & 3.11 & -2.889 & $0.004 *$ \\
\hline & BFM (kg) & 21.6 & 6.17 & 18.6 & 4.48 & -3.068 & $0.002 *$ \\
\hline & LBM (kg) & 73.4 & 9.40 & 73.1 & 8.38 & -0.369 & 0.712 \\
\hline
\end{tabular}

p $\overline{<0.05 * ~ k g ~=~ k i l o g r a m m e ; ~ B M I ~=~ B o d y ~ M a s s ~ I n d e x ; ~ B M R ~=~ B a s a l ~ M e t a b o l i c ~ R a t e ; ~ B F P ~=~ B o d y ~ F a t ~ P e r c e n t a g e ; ~}$ BFM = Body Fat Mass; LBM = Lean Body Mass

Table 3. Comparison of Pre-Test and Post-Test Values of Body Composition in the Resistance Training Group

\begin{tabular}{|c|c|c|c|c|c|c|c|}
\hline \multirow{2}{*}{ Variables } & & \multicolumn{2}{|c|}{ Pre-Test } & \multicolumn{2}{|c|}{ Post-Test } & \multirow{2}{*}{$\mathbf{t}$} & \multirow{2}{*}{$\mathbf{p}$} \\
\hline & & Mean & Sd & Mean & Sd & & \\
\hline \multirow{6}{*}{ 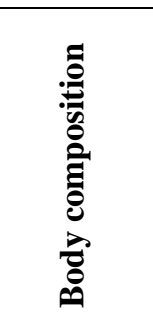 } & Body weight (kg) & 97.0 & 11.67 & 97.1 & 12.10 & -0.028 & 0.977 \\
\hline & BMI $\left(\mathrm{kg} / \mathrm{m}^{2}\right)$ & 27.4 & 1.92 & 27.4 & 1.99 & -0.029 & 0.977 \\
\hline & BMR & 2328.1 & 269.37 & 2366.6 & 277.83 & -2.953 & $0.003 *$ \\
\hline & ВFP \% & 18.7 & 3.82 & 17.2 & 3.93 & -2.727 & $0.006^{*}$ \\
\hline & BFM (kg) & 18.3 & 5.30 & 16.9 & 5.49 & -2.501 & $0.012 *$ \\
\hline & LBM (kg) & 78.7 & 8.07 & 80.1 & 8.26 & -3.111 & $0.002 *$ \\
\hline
\end{tabular}

p $<0.05 *$ kg = kilogramme; BMI = Body Mass Index; BMR = Basal Metabolic Rate; BFP = Body Fat Percentage; BFM = Body Fat Mass; LBM = Lean Body Mass

Table 4. Comparison of Pre-Test and Post-Test Differences of Aerobic Exercise and Resistance Exercise Group

\begin{tabular}{|c|c|c|c|c|c|c|c|}
\hline & \multirow{2}{*}{ Variables } & \multicolumn{2}{|c|}{$\begin{array}{l}\text { Aerobic Exercise } \\
\text { Group }\end{array}$} & \multicolumn{2}{|c|}{$\begin{array}{l}\text { Resistance Exercise } \\
\text { Group }\end{array}$} & \multirow{2}{*}{$\mathbf{t}$} & \multirow{2}{*}{ p } \\
\hline & & Mean & Sd & Mean & Sd & & \\
\hline \multirow{6}{*}{ 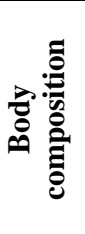 } & Body weight (kg) & 3.1 & 2.26 & -0.10 & -0.43 & -2.78 & $0.005^{*}$ \\
\hline & BMI $\left(\mathrm{kg} / \mathrm{m}^{2}\right)$ & 1.0 & 0.73 & 0.00 & -0.07 & -2.78 & $0.005^{*}$ \\
\hline & BMR & 23.2 & 37.12 & -38.50 & -8.46 & -2.73 & $0.006^{*}$ \\
\hline & BFP \% & 2.3 & 1.05 & 1.5 & -0.11 & -1.36 & 0.171 \\
\hline & BFM (kg) & 3.0 & 1.69 & 1.4 & -0.19 & -1.97 & $0.049^{*}$ \\
\hline & LBM (kg) & 0.3 & 1.02 & -1.4 & -0.19 & -2.59 & $0.009^{*}$ \\
\hline
\end{tabular}

p $<0.0{ }^{*}$ kg = kilogramme; BMI = Body Mass Index; BMR = Basal Metabolic Rate; BFP = Body Fat Percentage; BFM = Body Fat Mass; LBM = Lean Body Mass

\section{Discussion}

In this study, it was aimed to compare within- and between-group changes in body composition values of sedentary males who participated in 8-week aerobic and resistance exercise programs.

Statistically significant decreases were found out in body weight, body mass index, body fat percentage and body fat mass values of the aerobic training group. However, there were no statistically significant differences in basal metabolic rate and lean body mass values. Cardiorespiratory training is an effective training method for reducing body fat percentage, body fat mass, skinfold thickness and body weight in both men and women (Heyward, 1991). There are many studies in the literature on the effects of aerobic exercise on body composition (Çolakoğlu \& Karacan, 2006; Karacan \& Günay, 2003; Lee et al., 2010; Thompson, Rakow \& Perdue, 2004). Gökdemir et al. (2007) studied the effects of aerobic training on body fat rate with the help of the control and exercise groups, each with 15 participants. The exercise group participated in an aerobic training program for 3 days a week for total 8 weeks. The control group did not perform any training. As a result, it was found that aerobic training significantly reduced body fat and body weight. In another study conducted to investigate the effects of aerobic training administered 3 days a week for total 12 
weeks, Amano et al. (2000) found significant decreases in body weight, body mass index, body fat percentage and fat mass values of the individuals after the training program. However, there was no significant change in lean body mass. The findings of these studies are in line with ours. In order to reduce body weight and alter body composition, it is generally accepted that sustained endurance training is more advantageous than other training forms as it increases the energy expenditure. Endurance training is thought to play a role in increasing basal metabolic rate (Ballor, Poehlman, 1992). Nevertheless, in our study, no significant change was found in BMR values of the aerobic training group. Gilliat et al. (2001) examined the effects of physical activity on basal metabolic rate (BMR) in women aged 35-50 years divided into two groups as those who did physical exercise for an average of 9 hours per week and those who were sedentary. They evidently found that women doing physical exercises had a higher basal metabolic rate compared to sedentary ones. Broeder et al. (1992) examined the effect of aerobic fitness exercise on BMR in 69 men aged 18-35 years classified into three fitness groups as low, middle and high according to their $\mathrm{VO}_{2}$ Max capacities, and found statistically significant differences in BMR values between the groups.

No significant differences were found in body weight and body mass index values of the resistance training group. On the other hand, there was an increase in basal metabolic rates and it was found to be statistically significant. While significant decreases were detected in body fat percentage and fat mass and there was a significant increase in lean body mass values of the aforesaid group. Rahimi (2006) conducted a study where the effects of 12-week moderate and high-intensity strength training were examined regarding to body composition. At the end of the study, it was found that both intensities the training caused significant decreases in body weight, body fat percentage and body mass index values. It is known that lean body mass is one of the most important factors affecting basal metabolism because the tissues that are metabolically more active in the body mass are muscle tissues that make up lean body mass. The energy expended by muscle tissue is quite higher than fat tissue and has an important place in energy metabolism (Gilliat-Wimberly, Manore, Woolf, Swan \& Carroll 2001; Heyward, 1991;Rippe \& Hess, 1981). In their study, Lemmer et al. (2000) divided the participants into four groups as young men, young women, old men and old women. All groups participated in resistance training program planned by the researcher for 24 weeks. As a result of the study, it was discovered that there was a significant increase of $7 \%$ in BMR values. It was also determined that resistance training increases basal metabolic rate in some other studies (Smanepoe et al., 2013; Akbulut \& Rakıcıŏlu, 2012).

It was determined that body weight, body mass index and fat mass values of the aerobic training group reduced significantly compared to the resistance training group. On the other hand, basal metabolic rate and lean body mass values of the resistance training group significantly increased compared to the aerobic training group. There was no significant difference between the two groups by body fat percentage values. It has long been known that strength and endurance training enhance body composition and physical performance and improve the functional abilities of the body and health status. In addition, both training types cause an increase in lean body mass and a decrease in fat mass. Strength exercises increase lean body mass and the rate of respiration, reduce the total fat mass and greatly increase both the upper and lower body strength. Conversely, endurance training significantly changes body composition and promotes metabolic adaptations and maximum oxygen uptake, which leads to an increase in the training capacity. Although endurance training generally does not cause a significant muscle mass increase, it can be more effective than anaerobic resistance training in increasing maximal oxygen consumption (Lo, Lin, Yao \& Ma, 2011). Toraman et al. (2002) examined the effects of a 9-week training program on body composition in the elderly. In the study, both strength and endurance training were administered to the subjects for 9 weeks. At the end of the study, it was found that both types of training significantly reduced body weight, body fat percentage and body mass index values. Bryner et al. (1999) investigated the effects of a diet program followed along with strength and aerobic training. In the study, while the resting metabolic rate (RMR) values of the strength+diet group increased significantly, there was no significant difference between the RMR values of aerobic+diet group. When the RMR values of the two groups were compared to each other, the values of the strength training group were significantly higher.

\section{Conclusion}

In conclusion, it was determined that aerobic exercise reduced body composition values such as body weight, body mass index, body fat percentage and body fat mass, and resistance exercise reduced body fat percentage and body fat mass values but increased basal metabolic rate and lean body mass values. However, while body weight, body mass index and body fat mass values of the aerobic exercise group were expected to be reduced more than those of the resistance exercise group, the increase in basal metabolic rate and lean body mass was determined in favor of the resistance training group. Parallel to the literature, these findings suggest that regular long-term aerobic exercise is effective in reducing body fat percentage, body fat mass and body weight in both women and men. Besides, while resistance exercise is not considered as an effective way to lose weight, it is effective in reducing body fat mass and increasing lean body mass. 


\section{References}

Akbulut, G., \& Rakıcıoğlu, N. (2012). The effects of diet and physical activity on resting metabolic rate (RMR) measured by indirect calorimetry, and body composition assessment by dual-energy x-ray absorptiometry (DXA). Turk J Phys Med Rehab, 58, 1-8.

Akgün, N. (1995). The place of exercise in the treatment of obesity. Journal of Sports Medicine, 20(3), 91-103.

Amano, M., Kanda, T., Ue, H., \& Moritani, T. (2001). Exercise training and autonomic nervous system activity in obese individuals. Med Sci Sports Exerc. 33(8), 1287-1291. https://doi.org/10.1097/00005768-200108000-00007

Ballor, D. L., \& Poehlman, E. T. (1992). Resting metabolic rate and coronary-heart-disease risk factors in aerobically and resistance-trained women. Am J Clin Nutr. 56, 968-974. https://doi.org/10.1093/ajcn/56.6.968

Broeder, C. E., Burrhus, K. A., Svanevik, L. S., \& Wilmore, J. H. (1992). The effects of aerobic fitness on resting metabolic rate. Am J Clin Nutr. 55(4), 795-801. https://doi.org/10.1093/ajen/55.4.795

Bryner, R.W., Ullrich, I.H., Sauers, J., Donley, D., Hornsby, G., Kolar, M., \& Yeater, R. (1999). Effects of resistance vs. aerobic training combined with an 800 calorie liquid diet on lean body mass and resting metabolic rate. Journal of the American College of Nutrition. 18(1), 115-121. https://doi.org/10.1080/07315724.1999.10718838

Brzycki, M. (1993). Strength testing-predicting a one-rep max from reps-to-fatigue. JOPERD. 68, 88-90. https://doi.org/10.1080/07303084.1993.10606684

Büyükyazı, G., Ulman, C., Candan, N., Taneli, F., Özlen, N., \& Tıkız, H. (2005). Eight weeks of rapid tempo gait in cardiovascular disease risk factors in middle-aged men. Ege Medical Journal, 44, 161-166.

Carter, J. E. L., \& Heath, B. H. (1990). Somatotyping-Development and Application. Cambridge University Press,

Çolakoğlu, F. F., \& Karacan, S. (2006). The effect of aerobic exercise on some physiological parameters in young women and middle-aged women. Kastamonu Education Journal, 14(1), 277-284.

Elam, R. P., Hardin, D. H., Sutton, R. A., \& Hagen, L. (1989). Effects of arginine and ornithine on strength, lean body mass and urinary hydroxyproline in adult males. J Sports Med Phys Fitness. 29(1), 52-56.

Eric, T. P., Roman, V. D., Walter, F. D., Martin, B., \& Philip, A. A. (2000). Effects of resistance training and endurance training on insulin sensitivity in non-obese, young women: a controlled randomized trial. The Journal of Clinical Endocrinology \& Metabolism, 85(7), 2463-2468.

Fox, E. L., Bowers, R. W., Foss. M. L., \& Trans, M. C. (2012). The physiological basis of physical education and athletics. Ankara: Sports Publisher.

Gilliat-Wımberly. M., Manore, M. M., Woolf, K., Swan, P. D., \& Carroll, S. S. (2001). Effects of habitual physical activity on the resting metabolic rates and body compositions of women aged 35 to 50 years. Journal of the American Dietetic Association 101(10), 1181-1188. https://doi.org/10.1016/S0002-8223(01)00289-9

Gökdemir, K., Koç, H., \& Yüksel, O. (2007). The effect of aerobic training program on some respiratory and circulatory parameters and body fat ratio of university students. Journal of Exercise, 1(1).

Harbili, S., Özergin, U., Harbili, E., \& Akkuş, H. (2005). The effect of strength training on body composition and some hormones. Hacettepe J. of Sport Sciences, 16(2), 64-76.

Heyward, V. H. (1991). Advanced Fitness Assessment and Exercise Prescription. 2nd ed. Champaign, Human Kinetics Books.

Heyward, V. H. (1991).Advanced Fitness Assesment \& Exercise Prescription. Human Kinetics.

Karacan, S., \& Günay, M. (2003). The effect of aerobic training program on cardiovascular risk factors of menopausal women. Gazi Education Faculty Journal, 23(3), 257-273.

Karvonen, M. J., Kentala, E., \& Mustala, O. (1957). The effects of training on heart rate: a longitudinal study. Ann Med Exp Biol Fenn. 35, 307-315.

Katzmarzyk, P. T., Leon, A. S., Rankinen, T., Gagnon, J., Skinner, J. S., \& Wilmore, J. H., et al. (2001). Changes in blood lipids consequent to aerobic exercise training related to changes in body fatness and aerobic fitness. Metabolism. 50, 841-848. https://doi.org/10.1053/meta.2001.24190

Kaya, H., \& Özçelik, O. (2009) Comparison of effectiveness of body mass index and bioelectric impedance analysis methods on body composition in subjects with different ages and sex. FU Health Sci Med J. 23, 1-5.

Kurter, M., \& Öztürk, F. (1991). The effect of strength training on body composition in elite basketball players. Journal of Sport Sciences. 2(4), 9-15. 
Lee, Y. H., Song, Y. W., Kim, H. S., Lee, S. Y., Jeong, H. S., Suh, S.H., .. Hong, Y. M. (2010). The effects of an exercise program on anthropometric, metabolic, and cardiovascular parameters in obese children. Korean Circulation Journal. 40(4), 179-184. https://doi.org/10.4070/kcj.2010.40.4.179

Lemmer, J. T., Ivey, F. M., Ryan, A. S., Martel, G. F., Hurlbut, D. E., Metter, J. E., ... Hurley, B. F. (2001). Effects of strenght training on resting metabolic rate and physical activity: age and gender comparisons. Med Sci Sports Exerc. 33(4), 532-541. https://doi.org/10.1097/00005768-200104000-00005

Lemura, L. M., \& Amdreacci, J. (2000). Lipit and lipoprotein profiles, cardiovascular fitness, body composition and diet during and after resistance, aerobic and combination training in young woman. Eur. Journal Appl. Physiology, 82, 5-6. https://doi.org/10.1007/s004210000234

Lo, M. S., Lin, L. L., Yao, W. J., \& Ma, M. C. (2011). Training and detraining effects of the resistance vs. endurance program on body composition, body size, and physical performance in young men. Journal of Strength and Conditioning Research. 25(8), 2246-2254. https://doi.org/10.1519/JSC.0b013e3181e8a4be

Murtagh, E. M., Boreham, C. A., Nevill, A., Hare, L. G., \& Murphy, M. H. (2005). The effects of 60 minutes of brisk walking per week, accumulated in two different patterns, on cardiovascular risk. Prev Med. 41, 92-97. https://doi.org/10.1016/j.ypmed.2004.10.008

Osei-Tutu, K. B., \& Campagna, P. D. (2005). The effects of short- vs. long-bout exercise on mood, VO2max, and percent body fat. Prev Med. 40, 92-98. https://doi.org/10.1016/j.ypmed.2004.05.005

Özer, M. K. (2009). Kinanthropometry, Morphological Planning in Sport (2nd Edition). Istanbul: Nobel Publications.

Rahimi, R. (2006). Effect of moderate and high intensity weight training on the body composition of overweight men. Facta Universitatis Physical Education and Sport. 4(2), 93-101.

Rippe, J. M., \& Hess, S. (1981). The role of physical activity in the prevention and management of obesity. Journal of the American Dietetic Associationç. 10(98), 31-38.

Savaş, S., \& Sevim, Y. (1992). The effects of circular training method on general force development of female basketball players aged 14-16. Journal of Sports Sciences. 3(4), 40-47.

Swanepoel, M., De-Ridder, J. H., Wilders, C. J., Rooyen, J. V., Strydom, G. L., \& Ellis, S. (2013). The effects of a 12-week resistance training programme on the body composition and resting metabolic rate in a cohort of caucasian and coloured, premenopausal women aged 25-35 years. African Journal for Physical, Health Education, Recreation and Dance, 19(4).

Terry, J. H., Glen, O. J., Roger, A. H., Craig, J. C., \& William, G. T. (1988). Yearly changes in the body composition and muscular strength of high school wrestlers. Research Quarterly for Exercise and Sport, 59(3), 240-243. https://doi.org/10.1080/02701367.1988.10605510

Thompson, D. L., Rakow, J., \& Perdue, S. M. (2004). Relationship between accumulated walking and body composotion in middle-aged women. Medicine and Science in Sports and Exercise. 36, 911-914. https://doi.org/10.1249/01.MSS.0000126787.14165.B3

Toraman, F., Yaman. H., Şahin, G., Ayçem, N., \& Muratl, S. (2002). The effect of a 9-week training program on the body composition of the elderly. Geriatrics. 5(3), 91-96.

Utter, A. C., Whitcomb, D. C., Nieman, D. C., Butterworth, D. E., \& Vermillion, S. S. (2000). Effects of exercise training on gallbladder function in an obese female population. Medicine Science In Sports Exercise, 32(1), 41-45. https://doi.org/10.1097/00005768-200001000-00007

Zorba, E. (1999). Sports and Physical Fitness for All. Ankara: Meyir Printing House.

\section{Copyrights}

Copyright for this article is retained by the author(s), with first publication rights granted to the journal.

This is an open-access article distributed under the terms and conditions of the Creative Commons Attribution license which permits unrestricted use, distribution, and reproduction in any medium, provided the original work is properly cited. 